Johnson \& Wales University ScholarsArchive@JWU

Library Staff Publications

University Libraries

Winter 12-22-2017

\title{
Incivility and Dysfunction in the Library Workplace: Perceptions and Feedback from the Field
}

Richard J. Moniz Jr.

Johnson \& Wales University - Charlotte, richard.moniz@jwu.edu

Follow this and additional works at: https://scholarsarchive.jwu.edu/staff_pub

Part of the Collection Development and Management Commons, and the Industrial and Organizational Psychology Commons

\section{Repository Citation}

Moniz, Richard J. Jr., "Incivility and Dysfunction in the Library Workplace: Perceptions and Feedback from the Field" (2017). Library Staff Publications. 27.

https://scholarsarchive.jwu.edu/staff_pub/27

This Article is brought to you for free and open access by the University Libraries at ScholarsArchive@JWU. It has been accepted for inclusion in Library Staff Publications by an authorized administrator of ScholarsArchive@JWU. For more information, please contact jcastel@jwu.edu. 


\title{
Incivility and Dysfunction in the Library Workplace: Perceptions and Feedback from the Field
}

\begin{abstract}
Issues associated with lack of civility, less than ideal functionality and employees that may not self-reflect as much they should are all challenges in the modern workplace and libraries are no exception. The purpose of this study was to determine which issues associated with a lack of civility such as mobbing, bullying, workplace dysfunction, and lack of abilities regarding selfreflection were found in the library workplace and to what extent. The data represents the feedback of 4,168 library employees through a self-reporting survey instrument designed by the authors with the help of the American Library Association. Data is both quantitative and qualitative and seeks to examine the issues addressed across all types of libraries. While useful for all library employees, this study and report are especially relevant to the modern library administrator.
\end{abstract}

\section{Keywords}

Civility, bullying, library management, emotional intelligence, mobbing, workplace culture, harassment, conflict, conflict management, library jobs, communication

\section{Author Notes}

\author{
Jo Henry \\ Librarian \\ Charlotte Mecklenburg Library, Charlotte, NC \\ jahenry8@gmail.com
}

2234 Chestnut Lane, Matthews, NC 28104

Joe Eshleman

Librarian

Central Piedmont Community College, Charlotte, NC

kjeshleman@gmail.com

140 Parkview St, Davidson, NC 28036

Dr. Rebecca Croxton

Head of Assessment, J. Murrey Atkins Library

University of North Carolina at Charlotte, NC

racroxto@uncc.edu 
242 Rosedale Lane, Matthews, NC 28105

Dr. Richard Moniz (Corresponding author for proofs and other information)

Director of Library Services, Adjunct MLIS Instructor

Johnson \& Wales University, Charlotte, NC \& University of North Carolina at Greensboro, NC richard.moniz@jwu.edu

9109 Field Dove Court, Charlotte, NC 28210

Examining what it means to show civility or "be civil" at work can at first seem to be a trite exercise. Often, the most common incivilities can come as a surprise to those who did not consider them to be part of any workplace, much less a library. The common definition places emphasis on courtesy and politeness (Merriam Webster, 2017) and seems to be lacking in depth. A baseline of courteous and polite behavior may not equate to a stable civil workplace and within much behavior, there can be a spectrum of accepted and unaccepted instances. Despite this, workplace norms, standards and rules are in place to help reinforce mutual respect and lead to a common understanding of how to treat fellow library employees in addition to all whom librarians encounter.

Although in many ways it can be considered to be like any other workplace, there are characteristics of the library workplace that are unique in some respects. Within the historical context and objectives of libraries is the attempt to give equal access to information and knowledge in a setting primarily based on sharing rather than profit motives. This aspect of libraries describes one aspect of a singular work environment. Other related factors to consider are the pressure put on libraries, and therefore librarians, to work within limited budgets, cover numerous job responsibilities, and constantly work towards proving the overall value of services and skills and defending the sustainable future of libraries. These aspects may also be seen in other fields, including education. Such considerations are given voice to raise the question, "Is 
there something specific about library work environments that create or foster incivility or are libraries apt to experience the same dysfunctional relations issues as other types of workplaces?" Although this question is mostly indirectly addressed in this article, it is important to remember that findings such as these lead to these type of important inquires.

With this type of goal in mind, along with the survey results and the literature on the subjects of library incivility and dysfunction at hand, perhaps a key contributor to incivility that focuses on a lack of self-reflection is one of the most important elements to explore. It would seem at first that librarians, often concerned with how they are portrayed or stereotyped, have done a great deal of inward reflection. A common current theme in libraries questions the purported advancement librarians have made regarding equality and true equal access to information for all. In a similar way here, the perception that library workspaces are devoid of incivilities such as mobbing and bullying which lead to workplace dysfunction is brought into question.

This survey, which supports the idea of both the prevalence and recurring issues of incivilities in the library workplace, is troubling yet can also be a call to action. While awareness is often a first step to alleviating problems, there can also be backlash from those who find it surprising that there was a lack of awareness to begin with. However, the results from the survey feedback from a large sample can help to yield conversations that begin to shine light on these issues that affect a librarian's inability to achieve their full potential. The emphasis at the end of this article on improving social skills supports the philosophy that developing people who value and model civility creates actualized librarians who fulfill the most ideal tenets of librarianship. 


\section{Literature Review}

Pearson, Andersson, and Porath (2000) provide a useful definition of incivility in the workplace which is described as "rudeness and disregard toward others" (124). Others (Pearson, Andersson, \& Porath 2000; Blau \& Andersson 2005; Johnson \& Indvik 2001; Holm, Torkelson, \& Backström, 2015; Moniz, Henry, Eshleman, et al. 2016) further speculate on the causes of incivility noting that they may be attributed to workplace exhaustion, stress, social work climate, workplace norms, and workload. While these issues are not addressed directly in the authors' study described here, they do provide evidence that incivility in the workplace is a problem. Jordan (2014), in her exploration of public library stressors found similar issues uncovered in the study shared here by the authors. For example, Jordan discovered that "difficulty with coworkers" was one of the most significant public library workplace issues (p.298). According to Jordan (2014), “The more challenging tasks and some of the most common and highest ranked stressors [include]: problems with managers, problems with co-workers, and the workplace environment" (p. 304). This study brings relevance to the authors' study as it points specifically to the interactions in the library work environment as the cause of stress and problems. Supporting this perspective, the Civility in America Survey (2016) found that $43 \%$ of currently employed workers describe their leaders as uncivil. Other studies (Kim, Gear, \& Bielefield, 2017; Lim \& Lee, 2011; Reio \& Sanders-Reio, 2011) have also suggested that supervisors are often instigators of incivility. Additionally, co-workers have also been identified as potential contributors to negative work environments (Holm, Torkelson, \& Backstrom, 2015; Kim, Gear, \& Bielefield, 2017; Reio \& Sanders-Reio, 2011; Torkelson, Holm, Backstrom, \& Schad, 2016). While only Kim, Gear, and Bielefied's study (2017) is specific to libraries, all of these studies lend support for the authors' exploration of library employee roles linked to uncivil workplace 
actions. Again, all of these studies provided not only general information on the topic but also some specific areas for exploration as the authors sought to determine how relevant these specific challenges might be in the library workplace and between whom they most frequently occur.

With respect to the frequency of uncivil acts, a number of studies (Cortina, Magley, Williams, \& Langhout, 2001; Holm, Torkelson, \& Backstrom, 2015; Pearson, Andersson, \& Porath, 2000; Reio \& Sanders-Reio, 2011; Torkelson, 2016) point to the prevalence of incivility in the workplace. The 2016 Civility in America Survey of 1,126 adults study lends additional evidence to this perception indicating that $34 \%$ of Americans have experienced workplace incivility in their current or previous job. Because of these studies, the authors' included frequency in their survey questions. In their extensive interviews and polls covering fourteen years of workers representing a variety of professions, Porath and Pearson (2013) discovered that $98 \%$ of employees experience uncivil behavior at work at some point in time. This information too served as a benchmark against the authors' attempt to discover how frequently incivility occurred in the library as a workplace. While research of civility in libraries is limited, a study of academic librarians by Freedman and Vreven (2016) revealed "over 60\% of respondents reported three of the negative acts occurring at least "now and then"” (p. 737). These include work or person related and separately categorized physically intimidating acts (Freedmen and Vvreven 2016). As this study was library specific, it provided additional evidence that the frequency of uncivil acts in the library workplace needed to be explored further in the field.

One especially toxic level of incivility is found in workplace bullying. Crumpton (2014) describes this as "a persistent feeling of mistreatment or discomfort in the workplace from one or more individuals within common working relationships" (p. 17). A number of studies (Cowen, 
2012; Liefooghe \& Mackenzie, 2010; Niedhamer, David, \& Degioanni, 2007; Zabrodska \& Kveton, 2013) have revealed bullying is not uncommon in the work environment. These investigations suggested to the authors the act of bullying in the library workplace should be analyzed. In library specific research, Hollis found $62 \%$ of academic library staff impacted by bullying (2015). Likewise, Freedman's and Vreven's study in 2016 found 43\% of academic librarians experiencing bullying directly and 54\% witnessing bullying. While the Hollis (2015) and Freedman and Vreven (2016) studies focused on academic library staff, another study included both academic and public libraries finding $46 \%$ of workers experienced bullying (Kim, Gear, \& Bielefield, 2017). While bullying was measured differently in all of these studies, these figures indicate a significant presence in the library workplace and provided a starting point for further inquiry.

Cyberbullying is an emerging type of workplace bullying which deserves special treatment. This involves the "use [of] electronic devices and media to attack someone in almost any location, and at any time ..." (Corcoran, McGuckin, \& Prentice, 2015, p. 246). While research is relatively new in this area as it relates to work environments, in their merging of three separate studies, Coyne et al. (2016) found " $80-88 \%$ of participants experienced at least one form of cyber negative act in the previous six months ..." at work (p. 969). Again, their work serves as a general benchmark when considering the library environment and led to the inclusion of a question related to this in the authors' survey, especially since no library specific research was found to date.

Mobbing is another type of toxic incivility which can occur in the workplace. Leymann (1990) first brought attention to this type of incivility describing it as a "victim [who] is subjected to systematic stigmatizing" by "workmates or management" (p. 119). This is an action 
which "begins with an unresolved conflict and then spins wildly out of control to the detriment of an individual at the mercy of a group" (Hecker, 2007, p. 440). While no library specific studies have approached this issue, the concept of mobbing in the library has been discussed relative to the library workplace (e.g. Hecker, 2007; Motin, 2009; Leiding, 2010). Freedman and Vreven (2016) discussed the concept in their workplace civility study of academic librarians, but did not separate mobbing actions from other uncivil behaviors in their study. Because mobbing has been discussed and was included in Freedman and Vreven's (2016) study, the authors decided to include it in this study but separate it from bullying to provide some baseline data in the library field on this workplace behavior.

Another form of deviant work behavior explored in this study of workplace dysfunction was cyberloafing. Lim (2002) describes this as "the act of employees using their companies' Internet access for personal purposes during work hours" (p. 675). Findings from studies conducted by Blau, Yang, and Ward-Cook (2006) and Lim and Chen (2009) point to cyberloafing's most common forms as reading non-work related e-mails and browsing news websites. Similarly, Blanchard and Henle (2008) found 90\% of study participants engaging in non-work e-mail and browsing of online news or financial web sites. While some limited form of web surfing may be acceptable in libraries, it is included here since no library specific studies were found on this topic and these behaviors can lead to serious problems regarding fairness and responsibility.

The literature on Emotional intelligence (EI) is both deep and wide. It has been defined many times over but as its central proponent, Goleman (1997) has described it as "being able, for example, to rein in emotional impulse; to read another's innermost feelings; to handle relationships smoothly..." (p. xiii). This includes the areas of empathy, self-awareness, self- 
management, and social awareness, all of which have been shown to have a positive impact on civility or incivility in the workplace. Reflective of this study were prior investigations in the areas of counterproductive work behaviors and incivility. For example, Bibi, Karim, and Din (2013) found EI to reduce the impact of "abuse, production deviance, sabotage, theft, and withdrawal" among academic faculty (p. 323). To some degree, high EI has come to be viewed as a necessity for library leaders and managers (Crumpton, 2015). It was for this reason that EI was also explored in the authors' study.

Conflict management is another area addressed below which has been extensively researched and explored. Dijkstra, Beersma, and Evers (2011) note that conflict exists and causes challenges in every work environment. We should expect that libraries would be no different. According to Gabriel (2011):

Although there is a stereotype of the library as a calm oasis, I am sure that every librarian would scoff at the suggestion that conflict doesn't exist within our institutions. Whether it is with the communities we serve, our colleagues, or our supervisors, I find it hard to imagine any library_-just like any other workplace — without some level of conflict that needs to be managed and addressed. (p. 686)

Reasons for conflict and approaches to it can vary considerably. Writing in the Journal of Library Administration, Howland (2001) noted that diversity on a variety of levels and the changes that libraries began undergoing at the beginning of the century have contributed to this challenge. Just how prevalent workplace programs are that teach staff conflict management skills seems to be an open question which, while not addressed in prior studies, is addressed in the authors' study below. Numerous authors (Kautter, 2013; Mallappa \& Kumar, 2015) have noted the need to be proactive. This implies the need for developing skills. Again, much has been 
written on this topic and its importance but it would appear that no source has yet explored the prevalence of training for librarians.

An additional area explored by the authors was the prevalence of workplace dysfunction as a part of organizational culture. Schein (2004), a foremost scholar in the study of organizational culture, has defined it as including "(1) the beliefs, values, and assumptions of founders of organizations; (2) the learning experiences of group members as their organization evolves; (3) new beliefs, values, and assumptions brought in by new members and leaders" ( $p$. 225). Hicks (2014) has described the various ways that library cultures may specifically be explored, especially as it relates to the service mission of all libraries. Martin (2012) has highlighted the importance of not just developing but also maintaining elements of a positive and functional workplace culture in libraries. One of the best definitions of organizational dysfunction in general comes from Balthazard, Cook, and Potter (2006) who state, "The dysfunctional organization, much like a dysfunctional individual, is so characterized because it exhibits markedly lower effectiveness, efficiency, and performance than its peers or in comparison to societal standards" (p. 710). In her article entitled "People Make Libraries: Determining and Navigating Institutional Culture," Walker (2011) notes the importance of determining the relative function or dysfunction of a given library and associates it with whether or not one will fit in and be a happy and productive employee in the library's current environment. Until this study, there has been little attempt to quantify just how prevalent perceived dysfunction is in the library workplace. Because prior research points to a variety of causes for library dysfunction, the authors included open ended questions to better determine what specifically impacts libraries.

\section{Method}


Through extensive collaboration and discussion amongst three of the initial authors an instrument (included as an appendix at the end of this article) was developed to collect data on areas deemed significant in relation to incivility and dysfunction within libraries. The instrument was further refined with the assistance of Rob Christopher, Marketing Coordinator at the American Library Association. ALA then forwarded the link to the survey through a wide variety of email groups. In total, 85,813 people received the email, 4,829 people opened the email and clicked on the link, and 4,168 (approximately 5\% of those who received it and $86 \%$ of those who actually clicked into the link) responded. The survey was run and closed within a oneweek window in February of 2017.

The purpose of the instrument was to determine the prevalence of issues in the library workplace associated with incivility and dysfunction and to determine just how significant each of these issues were. Furthermore, it was determined to be all-inclusive with all types of libraries included in the data.

Once collected, the researchers ran descriptive and inferential statistics, including analysis of variance (ANOVA) on the quantitative data, and then collaborated in the interpretation of the qualitative elements collected. In addition to the original researchers, an experienced library researcher was added to provide additional insight, perspective and objectivity in interpreting the results.

\section{Results}

\section{Participant Demographics}

Overall, 4,168 individuals responded to at least a portion of the survey. The largest portion of participants were between the ages of 35 to $51(37.0 \%, \mathrm{n}=1536)$ and 52 to $70(43.5 \%$, $\mathrm{n}=1806)$, while the remaining participants were 21 to $34(17.4 \%, \mathrm{n}=721)$ or 71 and over $(2.0 \%$, 
$\mathrm{n}=85$ ). This seems to be at least somewhat representative of the field as a whole, as recent scholarship points to librarians as an aging population (Galbraith, Smith, and Walker, 2012; Rosa and Henks, 2017).

A large majority of respondents identified as female $(88.2 \%, \mathrm{n}=3648)$, while the remaining participants identified as male $(11.0 \%, \mathrm{n}=457)$, other $(0.1 \%, \mathrm{n}=5)$, or did not respond. These percentages are largely reflective of the profession (ALA reports males comprise $19 \%$ of the profession), though the sample for this study differs slightly (Rosa and Henks, 2017).

The vast majority of participants identified their race as White/Caucasian $(87.8 \%$, $\mathrm{n}=3439$ ). Despite efforts to garner more minority representation within the profession, this figure is representative of the current norm, with ALA reporting that $87 \%$ of librarians are White/Caucasian (Rosa and Henks, 2017). The remaining participants identified their race as Black or African-American $(3.4 \%, n=132)$, Hispanic or Latino $(2.3 \%, n=90)$, Asian or Pacific Islander $(1.9 \%, \mathrm{n}=74)$, American Indian or Alaskan Native $(0.1 \%, \mathrm{n}=5)$, two or more races $(2.9 \%, \mathrm{n}=115)$, or other $(1.5 \%, \mathrm{n}=60)$.

Almost two-thirds $(61.2 \%, \mathrm{n}=2508)$ of the participants reported working in public libraries, while the remaining participants listed academic libraries (23.2\%, $\mathrm{n}=952)$, school libraries $(10.0 \%, \mathrm{n}=412)$, special libraries $(3.0 \%, \mathrm{n}=112)$, and other $(2.6 \%, \mathrm{n}=107)$. With respect to library roles, just over a third of the survey participants $(36.3 \%, n=1483)$ were general or multifaceted librarians, followed by library administrators or managers $(28.0 \%, \mathrm{n}=1144)$, library assistants or paraprofessionals $(14.0 \%, \mathrm{n}=571)$, reference librarians $(8.9 \%, \mathrm{n}=362)$, media specialists/school librarians $(4.0 \%, \mathrm{n}=164)$, instruction librarians $(2.5 \%, \mathrm{n}=100)$, or other $(6.3 \%$, $\mathrm{n}=257)$.

\section{Incivility in the Workplace}


Survey participants were asked to reflect upon whether they had experienced incivility in the library workplace. Incivility in the survey was defined as "rude and discourteous behavior." Of the 4,050 individuals who responded to this question, $91.1 \%(n=3690)$ indicated that they had experienced incivility, while the remaining $8.9 \%(\mathrm{n}=360)$ indicated that they had not.

Respondents who had experienced incivility were asked to rate, at its most frequent point, how often they had experienced at least one uncivil act in the workplace. Nearly one-third $(30.9 \%, \mathrm{n}=122)$ of the participants indicated that they had experienced at least one uncivil act at work on a weekly basis and just over a quarter $(26.0 \%, \mathrm{n}=943)$ experienced an uncivil act on a monthly basis. Of the remaining participants, $15.8 \%(n=575)$ noted daily occurrences of experiencing an uncivil act, $16.5 \%(\mathrm{n}=601)$ on a yearly basis, and $10.8 \%(\mathrm{n}=391)$ within the past five years.

To assess whether there were significant differences related to the frequency of experiencing incivility in the workplace, the items for this survey question were transformed into Likert-type scale items in which 1=within the past five years, $2=y e a r l y, 3=$ monthly, $4=$ weekly, and 5=daily. Descriptive statistics related to this newly transformed variable "experiencing incivility" are outlined in Table 1. One-way analysis of variance (ANOVA) were conducted across all demographic factors collected for this study (age, gender, race, library type, and library role).

One-way ANOVAs and Fisher's Least Significant Difference (LSD) post-hoc comparisons (when appropriate) were calculated only for those samples meeting a minimum sample size, as calculating using $\mathrm{G}^{*}$ Power 3 using an a priori power analysis (Faul, Erdfelder, Bucher, \& Lang, 2009). Levene's test for homogeneity of variance was conducted for all ANOVA tests, with assumptions for this test met for all groups unless otherwise noted. When 
assumptions of homogeneity of variance were violated, Welch's adjusted ANOVA test and Games-Howell post-hoc analysis were used in place of the traditional ANOVA $F$ and LSD tests.

In the aggregate the mean rating for incivility, based upon the newly transformed 5-point scale ( $1=$ within the past five years / 5=daily), was $3.24(\mathrm{SD}=1.216)$, suggesting a slightly aboveaverage frequency of experiencing incivility in the workplace. Findings from one-way ANOVA analysis related to experiencing incivility in the workplace suggest that the frequency of occurrence differed significantly, based upon age $\left(\right.$ Welch's $F_{(3,273.54)}=26.569, p<.001, \eta_{p}{ }^{2}=$ $.022)$, type of library $\left(F_{(4,5330.1)}=6.674, p<.001, \eta_{p}{ }^{2}=.007\right)$, and role within the library $\left(\right.$ Welch's $\left.F_{(6,587.49)}=6.573, p<.001, \eta_{p}{ }^{2}=.011\right)$, though all with small effect sizes.

Post-hoc comparisons for age indicated that 21 to 34 year olds experienced incivility in the workplace significantly more often than those who were 52 to 70 years old and 71 years old and over. Similarly, individuals in the 35 to 51 years old category experienced incivility in the workplace significantly more often than those were 52 to 70 years old and 71 years old and over. Finally, individuals in the 52 to 70 years old category experienced workplace incivility significantly more often than those 71 years old and older. Post-hoc comparisons for library type revealed that public library employees experienced workplace incivility significantly more often than those employed in academic, school, and special libraries. Finally, post-hoc comparisons revealed that librarians (general or multifaceted), reference librarians, and paraprofessionals experienced incivility at work significantly more often than library administrators/managers. Table 1: Incivility, Witnessed Bullying, and Conflict Descriptive Statistics

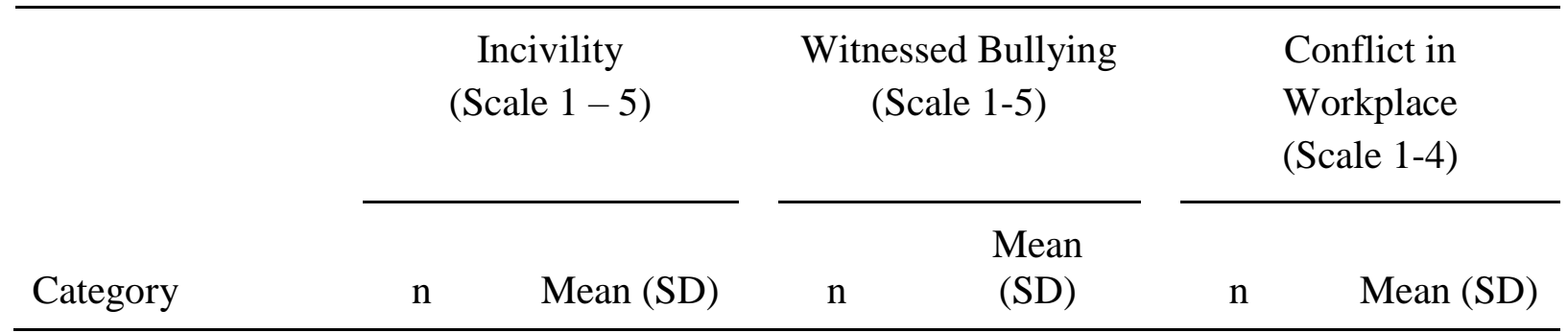


Age

\begin{tabular}{|c|c|c|c|c|c|c|}
\hline $21-34$ & 621 & $3.47(1.07)$ & 374 & $\begin{array}{c}3.47 \\
(1.11)\end{array}$ & 609 & $2.02(1.01)$ \\
\hline $35-51$ & 1352 & $3.35(1.21)$ & 870 & $\begin{array}{c}3.47 \\
(1.22)\end{array}$ & 1317 & $2.02(1.00)$ \\
\hline $52-70$ & 1588 & $3.10(1.24)$ & 995 & $\begin{array}{c}3.20 \\
(1.29)\end{array}$ & 1555 & $1.89(0.98)$ \\
\hline $71+$ & 59 & $2.44(1.29)$ & 40 & $\begin{array}{c}2.70 \\
(1.34)\end{array}$ & 63 & $1.57(0.89)$ \\
\hline \multicolumn{7}{|l|}{ Race * } \\
\hline Asian/PacIs & 64 & $3.09(1.28)$ & 37 & $\begin{array}{c}3.16 \\
(1.32)\end{array}$ & 62 & $1.94(1.01)$ \\
\hline Black/AfrAmer & 119 & $3.20(1.12)$ & 76 & $\begin{array}{c}3.26 \\
(1.16)\end{array}$ & 119 & $1.81(0.91)$ \\
\hline Hisp/Latino & 82 & $3.37(1.29)$ & 55 & $\begin{array}{c}2.95 \\
(1.35)\end{array}$ & 78 & $2.05(1.06)$ \\
\hline White/Cauc & 3020 & $3.24(1.21)$ & 1889 & $\begin{array}{c}3.37 \\
(1.24)\end{array}$ & 2961 & $1.95(0.99)$ \\
\hline 2 or More & 103 & $3.30(1.15)$ & 65 & $\begin{array}{c}3.32 \\
(1.21)\end{array}$ & 98 & $1.97(0.94)$ \\
\hline Other & 54 & $3.07(1.21)$ & 38 & $\begin{array}{c}3.18 \\
(1.39)\end{array}$ & 52 & $2.10(1.05)$ \\
\hline
\end{tabular}

Gender**

$\begin{array}{lrrrcrr}\text { Female } & 3214 & 3.26(1.21) & 2024 & \begin{array}{c}3.36 \\ (1.24)\end{array} & 3129 & 1.96(0.99) \\ \text { Male } & 380 & 3.15(1.25) & 235 & \begin{array}{c}3.12 \\ (1.28)\end{array} & 389 & 1.89(0.97)\end{array}$

Library Type

$\begin{array}{lrrrcrr}\text { Public } & 2300 & 3.32(1.19) & 1480 & \begin{array}{c}3.35 \\ (1.25)\end{array} & 2168 & 2.02(0.99) \\ & & & & & \\ \text { Academic } & 816 & 3.11(1.23) & 537 & \begin{array}{c}3.35 \\ (1.24)\end{array} & 847 & 1.92(0.98)\end{array}$




$\begin{array}{lcccccc}\text { School } & 337 & 3.16(1.28) & 145 & \begin{array}{c}3.18 \\ (1.20)\end{array} & 356 & 1.72(0.97) \\ \text { Special } & 102 & 3.00(1.31) & 66 & \begin{array}{c}3.29 \\ (1.23)\end{array} & 108 & 1.82(0.98) \\ & & & & & & \\ \text { Other } & 76 & 3.24(1.28) & 55 & 3.42 & 77 & 1.82(1.04) \\ & & & & (1.37) & & \end{array}$

Library Role

\begin{tabular}{lcccccc}
$\begin{array}{c}\text { Librarian } \\
\text { (gen.) }\end{array}$ & 1312 & $3.33(1.18)$ & 818 & $\begin{array}{c}3.42 \\
(1.20)\end{array}$ & 1300 & $1.96(1.00)$ \\
$\begin{array}{l}\text { Reference } \\
\text { Lib. }\end{array}$ & 325 & $3.45(1.12)$ & 211 & $\begin{array}{c}3.41 \\
(1.24)\end{array}$ & 321 & $2.05(0.98)$ \\
$\begin{array}{l}\text { Instruction } \\
\text { Lib. }\end{array}$ & 86 & $3.17(1.29)$ & 53 & 3.28 & 86 & $2.00(0.99)$ \\
Lib & 1059 & $3.10(1.24)$ & 716 & 3.27 & 1011 & $1.97(0.95)$ \\
Admin/Mgr & & & & $(1.28)$ & & \\
Paraprofess & 502 & $3.30(1.22)$ & 303 & $\begin{array}{c}3.29 \\
(1.25)\end{array}$ & 491 & $1.91(1.02)$ \\
& & & & 3.39 & 144 & $1.92(1.05)$ \\
Media Spec & 138 & $3.25(1.33)$ & 62 & $(1.03)$ & & \\
& & & & 3.39 & 202 & $1.81(1.01)$ \\
Other*** & 206 & $3.05(1.21)$ & 188 & $(1.35)$ & & \\
\hline
\end{tabular}

*Race - American Indian/Alaskan native excluded from analysis due to small sample size.

**Gender - transgender and other excluded from analysis due to small sample size.

***admin./mgr. not designating as Paraprofess. or Media spec.

Survey participants were provided an open-ended response item in which they were asked to describe incivility in their library workplace if it existed. Of the responses to this survey item, 2,186 of the survey participants described incivility in their workplace, 6 felt responding was unsafe, and 99 noted it was not an issue. Since responses were unlimited, often multiple examples of incivility were given within one response. Of all responses, $41.69 \%$ attributed incivility to communication methods which included negative and rude talk or yelling in the 
workplace. Behavioral-based incivility was noted in $39.59 \%$ of responses. These types of behavior include bullying, mobbing, disrespect, unprofessional actions, passive-aggressive behavior, shunning/ignoring, and moodiness.

\section{Bullying in the Workplace}

Survey participants were asked to reflect upon whether they had been bullied in the workplace and also whether they had witnessed bullying. In this study, bullying is defined as “persistent negative attacks which can be personal and/or work related." Overall, 40.1\% $(n=1583)$ of the respondents indicated that they had personally been bullied, while $59.0 \%$ $(n=2309)$ noted that they had witnessed bullying. An examination of the data related to being bullied by age revealed noteworthy variations among age groups; those between 52 to 70 years old had the highest frequency of being bullied (44.1\%, $n=758)$, followed by 35 to 51 years old (40.1\%, $\mathrm{n}=586), 21$ to 34 years old $(31.7 \%, \mathrm{n}=217)$, and 71 years old and over $(25.5 \%, \mathrm{n}=18)$. If an individual had been bullied in the workplace, they were asked to indicate who bullied them from a given list. Frequency ratings for this item are outlined in Table 2. Overall, nearly a third of the individuals who responded to this question cited their supervisors as the bully $(30.2 \%$, $\mathrm{n}=478)$, followed by peers/equally ranked co-workers $(20.6 \%, \mathrm{n}=325)$, higher ranking coworkers $(13.9 \%, \mathrm{n}=220)$, lower ranking co-workers $(12.3 \%, \mathrm{n}=194)$, and other $(23.0 \%, \mathrm{n}=364)$. This latter group allowed participants to write in so responses varied considerably, often including patrons, parents, or board members.

Table 2: Individuals Cited as Bullies

\begin{tabular}{lcc}
\hline Category & $\mathrm{n}$ & $\%$ of Total \\
\hline Higher ranking co-worker & 220 & 13.9 \\
Supervisor & 478 & 30.2
\end{tabular}


Peer/equally ranked co-worker

Lower ranking co-worker

Other
325

194

364
20.6

12.3

If an individual witnessed bullying behavior in the library workplace, they were asked to note how often they witnessed it at its most frequent point. Just over a third of the respondents indicated that they had witnessed bullying on a weekly basis $(35.6 \%, \mathrm{n}=812)$ and just under a quarter had witnessed bullying on a monthly basis $(23.9 \% \mathrm{n}=546)$. The remaining participants noted that they had witnessed bullying in the library workplace daily $(17.3 \%, \mathrm{n}=396)$, yearly $(10.3 \%, \mathrm{n}=235)$, or within the past five years $(12.9 \%, \mathrm{n}=295)$.

Similar to the analysis for incivility, the frequency measure for witnessing bullying in the workplace was transformed into a Likert-type scale in which $1=$ within the past five years, 2=yearly, $3=$ monthly, 4=weekly, and 5=daily. In the aggregate the mean rating for witnessing bullying in the workplace, based upon the newly transformed 5-point scale was $3.34(\mathrm{SD}=1.25)$, suggesting a slightly above-average frequency of witnessing bullying in the workplace. Descriptive statistics related to this newly transformed variable "witnessing bullying" are outlined in Table 1 above.

Findings from one-way ANOVA analyses related to witnessing bullying in the workplace suggest that the frequency of occurrence differed significantly based upon age (Welch's $F_{(3,182.5)}$ $\left.=11.83, \mathrm{p}<.001, \eta_{p}{ }^{2}=.016\right)$ and gender $\left.F_{(1,2257)}=7.50, p=.006, \eta_{p}{ }^{2}=.003\right)$, though with small effect sizes. With respect to age, Games-Howell post-hoc comparisons revealed that individuals in the 21 to 34 years old range witnessed bullying significantly more frequently than those in the 52 to 70 years old category. Similarly, individuals in the 35 to 51 years old category witnessed 
workplace bullying significantly more often than those in the 52 to 70 years old and the 71 years old and over categories.

\section{Cyberbullying and Mobbing}

In addition to addressing issues related to workplace bullying in general, participants were also asked to respond to questions related to cyberbullying (bullying carried out through the use of email or some other online setting) or mobbing (hostile and unethical actions targeted at one individual by multiple co-workers). Overall, $14.8 \%(n=573)$ of the survey participants indicated that they had experienced cyberbullying at the workplace, while $85.2 \%(n=3,290)$ had not. Similarly, only $16.8 \%(\mathrm{n}=643)$ of the participants indicated that they had experienced mobbing in the library workplace, while $83.2 \%(n=3,194)$ had not. When asked whether they had witnessed mobbing in the workplace, $20.1 \%(n=770)$ of the participants indicated that they had, while $79.9 \%(n=3,058)$ had not. Finally, only $1.4 \%(n=54)$ admitted that they had instigated bullying or mobbing actions at the library workplace, while the vast majority $(98.6 \%, \mathrm{n}=3,760)$ noted that they had not. For this question in particular, there is a noteworthy risk of self-report bias in the findings.

\section{Cyberloafing}

Survey participants were asked to respond to questions related to cyberloafing. In this study, cyberloafing is defined as significant use of the Internet at work for purposes that are not work related. Overall, $18.6 \%(n=682)$ admitted that they engaged in cyberloafing at work, while $81.4 \%(n=2,991)$ indicated that they did not. For this survey item, as with the one above, there is notable risk of self-report bias in the responses. If an individual engaged in cyberloafing at work, they were then asked to indicate what types of cyberloafing, from a given list (see Table 3).

Individuals were allowed to select all that apply. Among the cyberloafing activities, news 
$(78.9 \%, \mathrm{n}=538)$, social media $(55.1 \%, \mathrm{n}=376)$, and personal communication $(51.9 \%, \mathrm{n}=354)$

stood out. It should be noted that the percentages listed are based off the 682 total respondents to this survey item.

Table 3: Cyberloafing Activities

\begin{tabular}{lcc}
\hline Category & \multicolumn{2}{c}{$\begin{array}{c}\text { of } \\
\text { Cyberloafers }\end{array}$} \\
\hline News & 538 & 78.9 \\
Social Media & 376 & 55.1 \\
Personal communication (emails to friends, etc.) & 354 & 51.9 \\
Hobbies & 171 & 25.1 \\
e-Commerce & 134 & 19.6 \\
Music, videos, entertainment & & 18.6 \\
Other & 127 & 9.7 \\
\hline
\end{tabular}

\section{Dysfunction and Conflict}

Survey participants were asked whether their library workplace had a culture that seemed dysfunctional at times. In this study, dysfunctional was defined as "not operating normally or properly." Overall, 53.2\% $(\mathrm{n}=1,927)$ of the respondents indicated that they thought their library culture was dysfunctional at times, while the remaining $46.8 \%(n=1,696)$ did not. Participants were also provided an open-ended response item in which they were asked to describe why they thought it was dysfunctional. The responses for this question were coded by one of the researchers and confirmed by the group. Of critical importance here is how important leadership was regarded. Overall, the largest perception of dysfunction was deemed as stemming from weak 
leadership (30\% of all responses) and dictatorial leadership (16\%). Poor communication was also seen as a highly impactful issue with $20 \%$ selecting it as most damaging. Numerous other issues such as general personality conflicts, lazy coworkers, lack of trust, cronyism and a general lack of faith in managers or leaders were all deemed causes of institutional dysfunction.

Study participants were also asked about the frequency with which they experienced conflict in the workplace. Nearly half the respondents noted that they experienced workplace conflict either weekly $(23.6 \%, \mathrm{n}=839)$ or monthly $(25.1 \%, \mathrm{n}=894)$. The remaining respondents noted that they experienced workplace conflict on a daily basis $(7.8 \%, \mathrm{n}=277)$ or very infrequently, if at all $(43.5 \%, \mathrm{n}=1,547)$. Of those who indicated they experienced workplace conflict, it was most often with peers $(30.9 \%, \mathrm{n}=616)$, followed by patrons $(27.9 \%, \mathrm{n}=556)$, then supervisors $(17.8 \%, \mathrm{n}=355)$. Finally, participants were asked whether their library workplace provides conflict management training. Only $42.1 \%(n=1485)$ answered in the affirmative, with the remaining $57.9 \%(n=2045)$ noting that they were not provided with conflict management training.

Similar to the analyses for incivility and witnessing of bullying, the frequency measure for experiencing workplace conflict was transformed into a Likert-type scale in which 1=very infrequently, if at all, 2=monthly, 3=weekly, and 4=daily. In the aggregate, the mean rating for witnessing bullying in the workplace, based upon the newly transformed 4-point scale was 1.96 $(\mathrm{SD}=0.99)$, suggesting an average frequency of experiencing conflict in the workplace.

Descriptive statistics related to this newly transformed variable "experiencing conflict" are outlined in Table 1.

Findings from one-way ANOVA analyses related to experiencing conflict in the workplace suggest that the frequency of occurrence differed significantly based upon age 
$\left(F_{(3,3540)}=8.168, \mathrm{p}<.001, \eta_{p}{ }^{2}=.001\right)$ and library type $\left(F_{(4,3551)}=8.683, p<.001, \eta_{p}{ }^{2}=.001\right)$, though with small effect sizes. With respect to age, LSD post-hoc comparisons revealed that individuals in the 21 to 34 years old and 35 to 51 years old categories experienced workplace conflict significantly more frequently than those in the 52 to 70 years old and 71 years old and over categories. LSD post-hoc comparisons related to library type revealed that respondents working in public libraries experienced workplace conflict significantly more often than those working academic, school, and special libraries. Those working in academic libraries experienced workplace conflict significantly more often than those working in school libraries.

\section{Emotional Intelligence}

To gain a better understanding of library employees' perception of their strengths and weakness as they relate to EI, survey participants were asked whether they considered selfawareness, self-management, self-motivation, empathy and social skills to be among their strengths by checking a corresponding box next to each item. Participants were instructed to select all factors that applied to them. In a separate question, participants were asked to check a box next to these same factors if they considered them to be weaknesses or areas with which they could use improvement. Overall, the greatest number of participants considered empathy to be a strength $(70.4 \%, \mathrm{n}=2933)$, followed by self-awareness $(62.9 \%, \mathrm{n}=2621)$, self-motivation $(62.9 \%$, $\mathrm{n}=2620)$, self-management $(60.6 \%, \mathrm{n}=2527)$, and social skills $(54.6 \%, \mathrm{n}=2274)$. Conversely, $27.8 \%(n=1157)$ of the participants considered their social skills to be a weakness, followed by self-management $(22.0 \%, \mathrm{n}=915)$, self-motivation $(21.4 \%, \mathrm{n}=893)$, self-awareness $(17.1 \%$, $\mathrm{n}=712)$, and empathy (13.6\%, $\mathrm{n}=566)$. These factors are outlined in Table 4. 
Table 4: Emotional Intelligence Strengths and Weaknesses

\begin{tabular}{lccccc}
\hline & \multicolumn{2}{c}{ Strengths } & & \multicolumn{2}{c}{ Weaknesses } \\
\cline { 2 - 5 } \cline { 5 - 6 } $\begin{array}{l}\text { Emotional Intelligence } \\
\text { Factor }\end{array}$ & $\mathrm{n}$ & $\begin{array}{c}\text { Percent of } \\
\text { Total }\end{array}$ & & $\mathrm{n}$ & $\begin{array}{c}\text { Percent } \\
\text { of Total }\end{array}$ \\
\hline Self-awareness & 2621 & 62.9 & & 712 & 17.1 \\
Self-management & 2527 & 60.6 & & 915 & 22.0 \\
Self-motivation & 2620 & 62.9 & & 893 & 21.4 \\
Empathy & 2933 & 70.4 & & 566 & 13.6 \\
Social Skills & 2274 & 54.6 & & 1157 & 27.8 \\
\hline
\end{tabular}

\section{Do you have any suggestions for creating a more civil library workplace?}

Lastly, survey participants were given an open-ended response item in which they were encouraged to provide suggestions for creating a more civil library workplace. Overall, 1635 usable responses were received (e.g., something other than "not applicable" or "none"). Responses underwent a qualitative thematic analysis until five primary themes emerged from the data. The most noteworthy theme that emerged $(22.8 \%, n=373)$ was the need for a strong leadership team that is in tune with the dynamics and needs of both the library team and the library organization; leadership that sets the tone for a civil workplace, holds employees accountable for their behavior, and addresses issues of incivility as they arise. Closely related to leadership was a desire for clearly stated policies for expected behavior, zero tolerance for bullying, and written procedures for reporting and dealing with employee grievances that were 
safe, allowing employees to express their concerns without fear of retaliation of negative repercussion $(13.9 \%, \mathrm{n}=228$ responses $)$.

Following closely, $21.0 \%(n=344)$ of the survey respondents suggested a need for training for both library administrators and staff related to civility, conflict management, empathy, and customer service. Many respondents also suggested that most library administrators would benefit from managerial training, with findings suggesting that management skills are often lacking for many individuals promoted into supervisory/leadership roles. The need for clear and open communication among all library team members was noted by $16.9 \%(n=277)$ of the survey participants. Similarly, $14.9 \%(n=244)$ of the survey respondents thought their libraries would be more civil if people were courteous, respectful, and kind; what many respondents referred to as the "Golden Rule," treat others as you would hope to be treated.

\section{Discussion}

The response that was received both in terms of participants in our survey and follow up questions and interest in the topics we explored indicated that, unfortunately, library workers suffer from many of the same issues associated with a lack of civility in all its various forms as others. With $91 \%$ indicating that they have dealt with incivility and $47 \%$ indicating they do so daily or weekly it is a problem which needs to be addressed. In order to problem solve, however, a good starting point is to understand just which problems exist and how prevalent they are. That is what we hope we have accomplished here.

Overall, $40 \%$ of the respondents indicated that they had been bullied and $59 \%$ indicated that they had seen others being bullied. One possibility for this discrepancy is that some respondents were afraid, even in this anonymous survey, to report bullying. Another strong possibility is that many people may be bullied and yet not able to define what is happening to 
them as easily as an observer. In either case, this is a very significant problem. Bullying is a major societal issue at all levels. If library leaders are bullying or standing aside while bullying occurs, then other leadership needs to step in and/or training on anti-bullying needs to take place. Workers also need to have more avenues to safely report incidents of bullying without fear of reprisal.

Similarly, mobbing has been seen by $20 \%$ of the respondents, a number slightly higher than those who report experiencing it (17\%). Similar to bullying we can wonder if the respondents were afraid to report it or if they were, in some cases, unaware of being mobbed. Perhaps from the outside this is clearer as one can see more objectively how a staff member is treated by others. Mobbing, while much less prevalent than bullying, seems to be more perfidious and sinister. It indicates a situation where a gang or group of individuals have either tacitly or inadvertently engaged in efforts to torment a staff member. No matter what the circumstance, this is an issue that management needs to take very seriously. If there is an issue with an individual being mobbed, it needs to be addressed in a caring and professional way by a library manager. A clear message should be sent to all staff that behavior such as mobbing is entirely unacceptable in any modern workplace.

Cyberloafing is perhaps one of the "lesser" issues that we explored here but it can become abusive, especially when staff must do extra work to compensate for an unproductive employee who engages in such activities. This is perhaps also one of the most difficult elements to unpack. While only $19 \%$ of the respondents admit to cyberloafing it would be surprising to discover that the majority of library staff do not check personal emails, read an occasional news article, or engage in social networking while "on the clock." In fact, many librarians would argue that these activities overlap actual job duties such as updating the library's social networking or 
are fairly minimal, such as reading the news on a lunch break. Cyberloafing is a much greater issue than in the past since most library staff have access to online shopping, social media and personal communication sites and internet news. Managers need to model and explain at times what Internet usage is and is not acceptable in this regard.

Overall, $53 \%$ of the survey respondents indicated they work in a dysfunctional culture. Certainly all of the above from bullying and mobbing to extreme cyberloafing can be contributing factors. A variety of issues impact culture in general. But the issue of leadership, clearly rises to the top. While we expected dictatorial or micromanaging leaders to cause damage, the fact that weak leadership was a bigger issue was somewhat of a surprise at first. In scouring the data given in the short answer responses the picture becomes clearer. In many organizations the leader is not the bully or source of the problem per se. Rather, they turn away, perhaps due to an inability or unwillingness to handle conflict, when other staff engage in maladaptive behaviors that affect other library staff. Many library managers are in their role because of their personal skills, knowledge, and abilities regarding libraries, not necessarily due to management skills. Possible solutions could include more support and training for managers to handle and address conflict, especially personality conflict, within libraries. Our ideal of libraries and values that we serve as librarians should not blind us to the fact that we work with human beings and that can be messy and difficult with no clear or easy answers at times. Respect and trust are key facts here and these two items were mentioned in the feedback. A manager needs to not only address problems but foster trust and respect in all directions. Communication also needs to be effective, something that library leaders can help with through modeling and coaching. 
Getting back to the general issue of conflict, what stands out from the survey is not so much its prevalence as the simple issue that workers have not been trained to deal with it. While managers are obvious targets for such training, all employees could benefit. Only $42 \%$ of the respondents indicated that conflict resolution training is provided by their organization. That means the majority of library staff are unprepared to handle conflict. This needs to change.

One question which the survey explored that might not seem to address dysfunction directly was EI. This was done by breaking down elements of EI as described by Goleman (1997). These include self-awareness, self-management, self-motivation, empathy, and social skills. Dysfunction and lack of civility can have many causes. By employees focusing on their own EI, they can mitigate or at least better determine how to approach the kinds of problems and issues described above. It is not too big a leap to suggest that a lack of EI could lead one into greater chances of conflict as well. Not surprisingly, librarians see themselves as very empathetic. Hicks (2014) and others have documented this well in prior research indicating that librarians see themselves as serving and caring for others' needs. The self-reported relative shortcomings in social skills could suggest an area for improvement. Since the survey implicates communication and relationship challenges as paramount, much could be done to improve the social skills of those within the profession. Conference attendance, the creation of groups or teams to work on projects, and networking outside the library are all activities that would provide more opportunities for staff growth.

Lastly, one of the curious factors uncovered in this study was a potential difference between age groups in perceived exposure to various forms of incivility and the ability to apply EI. While this study did not have the focus and numbers to do so, further research on this and other differences across groups within the library should warrant further investigation. 


\section{References}

Balthazard, P., Cook, R. \& Potter, R. (2006). Dysfunctional culture, dysfunctional organization: Capturing the behavioral norms that form organizational culture and drive performance. Journal of Managerial Psychology, 21(8), 709-732.

Bibi, Z., Karim, J., \& ud Din, S. (2013). Workplace incivility and counterproductive work behavior: Moderating role of emotional intelligence. Pakistan Journal of Psychological Research, 28(2), 317-334.

Blanchard, A. L. \& Henle, C. A. (2008). Correlates of different forms of cyberloafing: the role of norms and external locus of control. Computer in Human Behavior 31(4), 343-353.

Blau, G. \& Andersson, L. (2005). Testing a measure of instigated workplace incivility. Journal of Occupational and Organizational Psychology, 78, 595-614.

Blau, G., Yang, Y., \& Ward-Cook, K. (2006). Testing a measure of cyberloafing. Journal of Allied Health, 35(1), 9-17.

Civility in America VII: the state of civility. Weber Shandwick. Retrieved from http://www.webershandwick.com/uploads/news/files/Civility_in_America_the_State_of_ Civility.pdf

Corcoran, L., McGuckin, C., \& Prentice, G. (2015). Cyberbullying or cyber aggression? A review of existing definitions of cyber-based peer-to-peer aggression. Societies 5(2) 245255.

Cortina, L.M., Magley, V.J., Willams, J.H., \& Langhout, R.D. (2001). Incivility in the workplace: Incidence and impact. Journal of Occupational Health Psychology 6(1), 6480 .

Cowan, R. L. (2012). It's complicated: Defining workplace bullying from the human resource professional's perspective. Management Communication Quarterly 26(3), 377-403

Coyne, L., Farley, S., Axtell, C., \& Sprigg, C. (2016). Understanding the relationship between experiencing workplace cyberbullying, employee mental strain and job. The International Journal of Human Resource Management 28(7), 945-972.

Crumpton, M. (2014). The costs of having a bully in the library. The Bottom Line: Managing Library Finances 27(1), 17-21. 
Crumpton, M. (2015). The emotionally intelligent mentor. In Hines, S. \& Simons, M. Library Staffing for the Future (Eds.), (29-58). Bingley, UK: Emerald.

Dijkstra, M., Beersma, B. \& Evers, A. (2011). Reducing conflict-related employee strain: The benefits of an internal locus of control and a problem-solving conflict management strategy. Work \& Stress, 25(2), 167-184.

Faul, F., Erdfelder, E., Buchner, A., \& Lang, A. G. (2009). Statistical power analyses using G*Power 3.1: Tests for correlation and regression analyses. Behavior Research Methods, $41,1149-1160$.

Freedman, S. \& Vreven, D. (2016). Workplace incivility and bullying in the library: perception or reality? College \& Research Libraries 77(6), 728.

Gabriel, R. (Fall 2011). Managing conflict. Law Library Journal 103(4), 685.

Galbraith, Q., Smith, S., \& Walker, B. (2012). A case for succession planning: How academic libraries are responding to the need to prepare future leaders. Library Management, 33(4/5), 221-240.

Goleman, D. (1997). Emotional intelligence. New York, NY: Bantam Books.

Hecker, T.E. (2007). Workplace mobbing: a discussion for librarians. Journal of Academic Librarianship 33(4), 439-445.

Hicks, D. (2014). The construction of librarians' professional identities: A discourse analysis. Canadian Journal of Information \& Library Sciences, 38(4), 251-270.

Holm, K., Torkelson, E., \& Backströ, M. (2015). Models of workplace incivility: The relationships to instigated incivility and negative outcomes. BioMed Research International, Article ID 920239, doi:10.1155/2015/920239

Howland, J. (2001). Challenges of working in a multicultural environment. Journal of Library Administration 33(1/2), 105-123.

Johnson, P.R. and Indvik, J. (2001). Rudeness at work: impulse over restraint, Public Personnel Management, 30, 457-465.

Jordan, M.W. (2014). All stressed out but does anyone notice? Stressors affecting public libraries. Journal of Library Administration 54(4), 291-307. 
Jordan, P.J. \& Ashkanasy, N.M. (2002). Emotional intelligence as a moderator of emotional and Behavioral reactions to job insecurity. Academy of Management Review 27(3), 361-372.

Kautter, M. (2013). Advocating for the devil: Transforming conflict in libraries. Retrieved from http://www.ala.org/acrl/sites/ala.org.acrl/files/content/conferences/confsandpreconfs/201 3/papers/Krautter_Advocating.pdf

Kim, H., Gear, A., \& Bielefield, A. (2017). Bullying in the library workplace. Library Leadership and Management, 31(4).

Leiding, R. (2010). Mobbing in the library workplace. College \& Research Library News 71(7), 364-384.

Leymann, H. (1990). Mobbing and Psychological Terror at Workplaces. Violence and Victims $5(2), 119-126$.

Liefooghe, A., \& Mackenzie, K. (2010). The language and organization of bullying at work. Administrative Theory \& Praxis 32(1), 71-95.

Lim. V. K.G. (2002). The IT way of loafing on the job: cyberloafing, neutralizing and organizational Justice. Journal of Organizational Behavior 23(5), 675-694.

Lim, V. K.G. \& Chen, D. J. Q. (2009). Cyberloafing at the workplace: gain or drain on work? Behavior \& Information Technology 31(4), 343-353.

Lim, S. \& Lee, A. (2011). Work and nonwork outcomes of workplace Incivility: does family Support help? Journal of Occupational Health Psychology, 16(1), 95-111.

Mallappa, V. \& KS, M.K. (May 2015). Conflict management in management library professionals. DESIDOC Journal of Library \& Information Technology, 35(3), 200-205.

Martin, J. (2012). Symbols, sagas, rites, and rituals: An overview of organizational culture in libraries. C\&RL News, 73(6), 348-349.

Merriam Webster. (2017, November 10). Civility. Retrieved from https://www.merriamwebster.com/dictionary/civility

Moniz, R., Henry, J., Eshleman, J., Moniz, L., \& Slutzky, H. (2016). Stressors and librarians: how mindfulness can help. C\&RL News, 77(11), 534-536. 
Motin, S. H. "Bullying or mobbing: is it happening in your academic library?" Presentation at the ACRL 14th National Conference, Seattle, Washington, March 12-15, 2009.

Niedhammer, I., David, S., \& Degioanni, S. (2007). Economic activities and occupations at high Risk for workplace bullying: results from a large-scale cross-sectional survey in the General working population in France. International Archives of Occupational and Environmental Health 80(4), 346-353.

Pearson, C.M., Andersson, L.M., and Porath, C.L. (2000). Assessing and attacking workplace Incivility. Organizational Dynamics, 29, 123-137.

Porath, C., \& Perason, C. (2013). The price of incivility. Harvard Business Review 91, 114-121.

Reio, T.G., Jr. \& Sanders-Reio, J. (2011). Thinking about workplace engagement: Does Supervisor and coworker incivility really matter? Advances in Developing Human Resources, 13(4), 462.

Rosa, K. \& Henke, K. (2017). 2017 ALA demographic study. Retrieved from http://www.ala.org/research/sites/ala.org.research/files/content/Draft\%20of\%20Member \%20Demographics\%20Survey\%2001-11-2017.pdf

Schein, E. (2004). Organizational Culture and Leadership. San Francisco, CA, Jossey-Bass.

Torkelson, E., Holm, K. Bäckström, M. \& Schad, E. (2015). New types of employment, new ways to be uncivil? A thematic analysis of temporary agency workers' exposure to incivility. Psychology, 7(1), 74-84.

Torkelson, E., Holm, K. Bäckström, M. \& Schad, E. (2016). Factors contributing to the perpetration of workplace incivility: the importance of organizational aspects and experiencing incivility from others. Work and Stress, 30(2), 115-131.

Walker, S. (2011). Determining and navigating institutional culture. The Bottom Line, 24(2), 113-117.

Zabrodska, K. \& Kyeton, P. (2013). Prevalence and forms of workplace bullying among university employees. Employee Responsibilities and Rights Journal 25, 89-108. 


\section{Appendix}

\section{Library Workplace Civility Survey}

What is your age?

- 21 to 34

- 35 to 51

- 52 to 70

- 71 or older

What is your gender?

- Female

- Male

- Other

- Prefer Not to Say

What is your ethnicity? (Please select all that apply.)

- American Indian or Alaskan Native

- Asian or Pacific Islander

- Black or African American

- Hispanic or Latino

- White / Caucasian

- Prefer not to answer

- Other (please specify)

What type of library do you work in?

- Public

- University

- College

- Community College

- School

- Special

- Other

What type of position do you hold? 
- Librarian (general or multifaceted)

- Reference Librarian

- Instruction Librarian

- Library Administration or Management

- Library Assistant or Paraprofessional

- Media Specialist

- Other

Have you ever experienced incivility in the library workplace (Incivility is defined as rude and discourteous behavior.)?

- Yes

- No

If you have experienced incivility at work, at its most frequent point how often have you experienced at least one uncivil act?

- Daily

- Weekly

- Monthly

- Yearly

- Within the past 5 years

Have you ever been bullied in the library workplace? (Bullying is defined as persistent negative attacks which can be personal and/or work related.)

- Yes

- No

If you have been bullied in the workplace, who bullied you?

- Higher ranking co-worker

- Supervisor

- Peer/equally ranked co-worker

- Lower ranking co-worker

- Other (please specify) 
Have you ever witnessed bullying in the library workplace?

- Yes

- No

If you did witness bullying behavior in the library workplace how often did you witness it at its most frequent point?

- Daily

- Weekly

- Monthly

- Yearly

- Within the past 5 years

- $\mathrm{n} / \mathrm{a}$ (I answered no to the question about witnessing bullying)

Have you ever experienced cyberbullying in the library workplace? (Cyberbullying is bullying carried out through the use of email or some other online setting.)

- Yes

- No

Have you ever experienced mobbing in the library workplace? (Mobbing is hostile and unethical actions targeted at one individual by multiple co-workers.)

- Yes

- No

Have you ever witnessed mobbing in the library workplace?

- Yes

- No

Have you ever instigated bullying or mobbing actions?

- Yes

- No

If incivility exists in your library workplace please describe it briefly. 
Do you personally engage in cyberloafing at work? (Cyberloafing is defined as significant use of the internet at work for purposes that are not work related.)

- Yes

- No

If you engage in cyberloafing at work, what do you do? (Check all that apply)

- Music

- Videos

- Entertainment News

- Hobbies

- e-Commerce

- Personal communication (e-mails to friends, etc.)

- Social Media

- Other (please specify)

Does your library workplace have a culture that you meet deem dysfunctional at times?

(Dysfunctional is defined as not operating normally or properly.)

- Yes

- No

If your library does have a dysfunctional workplace culture at times, please describe why you would consider it dysfunctional.

How often do you experience conflict in the library workplace?

- Daily

- Weekly

- Monthly

- Very infrequently if at all

If you experience conflict in the library workplace, who is it most often with?

- Supervisor

- Peer

- Patrons

- Other (please specify) 
Does your library workplace provide you with any conflict management training?

- Yes

- No

Which of the following would you consider personal strengths? (Please select all that apply)

- Self-awareness

- Self-management

- Self-motivation

- Empathy

- Social Skills

Which of the following would you consider weaknesses or areas that you could use improvement with? (Please select all that apply)

- Self-awareness

- Self-management

- Self-motivation

- Empathy

- Social Skills

Do you have any suggestions for creating a more civil library workplace? 